\title{
Common Fixed Point for Weakly Compatible Mappings in Menger Spaces
}

\author{
Jay G. Mehta \\ Research Scholar (JRF) \\ Harish Chandra Research Institute \\ Allahabad. (INDIA)
}

\author{
M.L.Joshi \\ Associate Professor \\ Department of Mathematics \\ M. \& N. Virani Science College \\ Rajkot, India
}

\begin{abstract}
In this paper the concept of weakly compatible map in complete Menger PM space has been applied to prove common fixed point theorem via an implicit relation by using the common property (E.A).
\end{abstract}

\section{Mathematics Subject Classification 47H10, 54H25.}

\section{Keywords}

Common fixed point, Menger space, compatible maps, weakly compatible maps.

\section{INTRODUCTION}

Menger [1] has introduced the theory of probabilistic metric spaces in which a distribution function was used instead of nonnegative real number as value of the metric. Sehgal [2] initiated the study of contraction mapping theorems in probabilistic metric spaces. Since then several generalizations of fixed point Sehgal et al. [3], Sherwood [4], and Istratescu and Roventa [5] have obtained several theorems in probabilistic metric space. The study of fixed point theorems in probabilistic metric spaces is useful in the study of existence of solutions of operator equations in probabilistic metric space and probabilistic functional analysis. Altun and Turkoglu [6] proved two common fixed point theorems on complete FM-space with an implicit relation.

Jungck [7] introduced the notion of compatible mappings and utilized the same to improve commutativity conditions in common fixed point theorems. This concept has been frequently used to prove existence theorems on common fixed points. However, the study of common fixed points of non compatible mappings is also equally interesting which was initiated by Pant [8]. Recently, Aamri and Moutawakil [9] and Liu et al. [10] respectively, defined the property (E.A) and the common property (E.A) and proved some common fixed point theorems in metric spaces. Imdad et al. [11] extended the results of Aamri and Moutawakil [9] to semi metric spaces. Most recently, Kubiaczyk and Sharma [12] defined the property (E.A) in PM spaces and used it to prove results on common fixed points wherein authors claim to prove their results for strict contractions which are merely valid up to contractions.

Branciari [13] proved a fixed point result for a mapping satisfying an integral-type inequality which is indeed an analogue of contraction mapping condition. In recent past, several authors [14-18] proved various fixed point theorems employing relatively more general integral type contractive conditions. In one of his interesting articles, Suzuki [19] pointed out that Meir-
Keeler contractions of integral type are still Meir-Keeler contractions. In this paper, we prove the fixed point theorems for weakly compatible mappings via an implicit relation in Menger PM spaces satisfying the common property (E.A) .

\section{PRELIMINARIES}

we recall some definitions and known results.

Definition 2.1. A mapping $\mathrm{F}: \mathrm{R} \rightarrow \mathrm{R}^{+}$is called a distribution if it is non-decreasing left continuous with inf $\{F(t): t \in R\}=0$ and $\sup \{\mathrm{F}(\mathrm{t}): \mathrm{t} \in \mathrm{R}\}=1$.

We shall denote by $\mathrm{L}$ the set of all distribution functions while $\mathrm{H}$ will always denote the specific distribution function defined by

$$
H(t)=\left\{\begin{array}{l}
0, t \leq 0 \\
1, t>0
\end{array}\right.
$$

Definition 2.2. A mapping $\mathrm{t}:[0,1] \mathrm{x}[0,1] \rightarrow[0,1]$ is called a continuous $t$-norm if it satisfies the following conditions:

$$
\begin{array}{ll}
(\mathrm{t}-1) & \mathrm{t} \text { is commutative and associative; } \\
(\mathrm{t}-2) & \mathrm{t}(\mathrm{a}, 1)=\mathrm{a} \text { for all } \mathrm{a} \in[0,1] \\
(\mathrm{t}-3) & \mathrm{t}(\mathrm{a}, \mathrm{b}) \leq \mathrm{t}(\mathrm{c}, \mathrm{d}) \text { for } \mathrm{a} \leq \mathrm{c}, \mathrm{b} \leq \mathrm{d} .
\end{array}
$$

The following are the basic t-norms:

$$
\begin{aligned}
& T_{M}(x, y)=\operatorname{Min}\{x \cdot y\} \\
& T_{P}(x, y)=x \cdot y \\
& T_{L}(x, y)=\operatorname{Max}\{x+y-1,0\} .
\end{aligned}
$$

Definition 2.3. A probabilistic metric space (PM-space) is an ordered pair $(\mathrm{X}, \mathrm{F})$ consisting of a non empty set $\mathrm{X}$ and a function $\mathrm{F}: \mathrm{X} \times \mathrm{X} \rightarrow \mathrm{L}$, where $\mathrm{L}$ is the collection of all distribution functions and the value of $F$ at $(u, v) \in X \times X$ is represented by $F_{u, v}$. The function $F_{u, v}$ is assumed to satisfy the following conditions:

$(\mathrm{PM}-1) \mathrm{F}_{\mathrm{u}, \mathrm{v}}(\mathrm{x})=1$, for all $\mathrm{x}>0$ if and only if $\mathrm{u}=\mathrm{v}$;

$(\mathrm{PM}-2) \mathrm{F}_{\mathrm{u}, \mathrm{v}}(0)=0$;

$(\mathrm{PM}-3) \mathrm{F}_{\mathrm{u}, \mathrm{v}}=\mathrm{F}_{\mathrm{v}, \mathrm{u}}$;

$(\mathrm{PM}-4)$ If $\mathrm{F}_{\mathrm{u}, \mathrm{v}}(\mathrm{x})=1$ and $\mathrm{F}_{\mathrm{v}, \mathrm{w}}(\mathrm{x})=1$ then $\mathrm{F}_{\mathrm{u}, \mathrm{w}}(\mathrm{x}+\mathrm{y})=1$ for all $\mathrm{u}, \mathrm{v}, \mathrm{w}$ in $\mathrm{X}$ and $\mathrm{x}, \mathrm{y}>0$

Definition 2.4. A Menger space is a triplet $(\mathrm{X}, \mathrm{F}, \mathrm{t})$ where $(\mathrm{X}, \mathrm{F})$ is a PM-space and $\mathrm{t}$ is a t-norm such that the inequality

$(P M-5) F_{u, w}(x+y) \geq t\left\{F_{u, v}(x), F_{v, w}(x)\right\}$ for all $u, v, w$ in $X$ and $\mathrm{x}, \mathrm{y}>0$. 
Definition 2.5. A sequence $\left\{x_{n}\right\}$ in a Menger space $(X, F, t)$ is said to converges to a point $\mathrm{x}$ in $\mathrm{X}$ if and only if for each $\varepsilon>0$ and $\mathrm{t}>0$, there is an integer $\mathrm{M}(\varepsilon) \in \mathrm{N}$ such that

$$
\mathrm{F}_{x_{n}, x}(\varepsilon)>1-\mathrm{t} \text { for all } \mathrm{n} \geq \mathrm{M}(\varepsilon)
$$

Definition 2.6. The sequence $\left\{\mathrm{x}_{\mathrm{n}}\right\}$ is said to be Cauchy sequence if for $\varepsilon>0$ and $\mathrm{t}>0$, there is an integer $\mathrm{M}(\varepsilon) \in \mathrm{N}$ such that

$$
\mathrm{F}_{x_{n}, x_{m}}(\varepsilon)>1-\mathrm{t} \text { for all } \mathrm{n}, \mathrm{m} \geq \mathrm{M}(\varepsilon)
$$

Definition 2.7 A Menger PM-space (X, F, t) is said to be complete if every Cauchy sequence in $\mathrm{X}$ converges to a point in $\mathrm{X}$.

A complete metric space can be treated as a complete Menger space in the following way:

Lemma 2.1 If $(X, d)$ is a metric space then the metric $d$ induces mappings $F: X \times X \rightarrow L$, defined by $F_{p . q}=H(x-d(p, q))$, $\mathrm{p}, \mathrm{q} \in \mathrm{X}$, where $\mathrm{H}(\mathrm{k})=0$ for $\mathrm{k} \leq 0$ and $\mathrm{H}(\mathrm{k})=1$ for $\mathrm{k}>0$.

Further if, $\mathrm{t}:[0,1] \mathrm{x}[0,1] \rightarrow[0,1]$ is defined by $\mathrm{t}(\mathrm{a}, \mathrm{b})=\min \{\mathrm{a}, \mathrm{b}\}$. Then $(\mathrm{X}, \mathrm{F}, \mathrm{t})$ is a Menger space. It is complete if $(\mathrm{X}, \mathrm{d})$ is complete.

The space $(\mathrm{X}, \mathrm{F}, \mathrm{t})$ so obtained is called the induced Menger space.

Definition 2.8 A pair (f, S) of self-mappings of a Menger space $(\mathrm{X}, \mathrm{F}, \mathrm{t})$ is said to be weakly compatible if they commute at a coincidence point, that is, $\mathrm{fp}=\mathrm{Sp}$ for some $\mathrm{p} \in \mathrm{X}$ implies that $\mathrm{fSp}=\mathrm{Sfp}$.

Definition 2.9 A pair (f, S) of self-mappings of a Menger space $(\mathrm{X}, \mathrm{F}, \mathrm{t}$ ) is said to satisfy the property (E.A) if there exist a sequence $\left\{x_{n}\right\}$ in $\mathrm{X}$ such that

$$
\lim _{n \rightarrow \infty} f x_{n}=\lim _{n \rightarrow \infty} S x_{n}=t \text { for some } t \in X
$$

Definition 2.10 Two pairs (f, S)and (g, T) of self-mappings of a Menger PM space (X, F, t) are said to satisfy the common property (E.A) if there exist two sequences $\left\{x_{n}\right\},\left\{y_{n}\right\}$ in $\mathrm{X}$ and some $t$ in $X$ such that

$$
\lim _{n \rightarrow \infty} f x_{n}=\lim _{n \rightarrow \infty} S x_{n}=\lim _{n \rightarrow \infty} g y_{n}=\lim _{n \rightarrow \infty} T y_{n}=t
$$

\section{MAIN RESULT}

\subsection{Implicit Relations}

Let $\mathbf{F}^{*}$ be the set of real continuous functions

\begin{tabular}{|c|c|}
\hline$\left(\mathbf{F}^{*} 1\right)$ & $\varphi(u, 1, u, 1, u)<1$ \\
\hline$\left(\mathbf{F}^{*} 2\right)$ & $\varphi(u, u, 1, u, 1)<$ \\
\hline$\left.F^{*} 3\right)$ & $\varphi$ \\
\hline
\end{tabular}
$\varphi\left(t_{1}, t_{2}, t_{3}, t_{4}, t_{5}\right)=[0, \infty)^{5} \rightarrow R \quad$ satisfying the following conditions:

For all $\mathrm{u} \in(0,1)$,
Example : Define $\varphi\left(t_{1}, t_{2}, t_{3}, t_{4}, t_{5}\right)=[0, \infty)^{5} \rightarrow R$ as

$$
\varphi\left(t_{1}, t_{2}, t_{3}, t_{4}, t_{5}\right)=t_{1}-t_{2}+t_{3}-t_{4}-t_{5}
$$

Then clearly $\varphi$ is a continuous function such that for all $\mathrm{u} \in(0,1)$

$$
\varphi(u, 1, u, 1, u)=u-1+u-1-u=u-2<1 .
$$

$$
\varphi(u, u, 1, u, 1)=u-u+1-u-1=-u<1 .
$$

$\left(\mathbf{F}^{*} 3\right)$

$$
\varphi(1, u, u, 1, u)=1-u+u-1-u=-u<1 .
$$

For our main result first we prove the following lemma.

Lemma 3.1 Let $f, g, S$ and $T$ be self-mappings on a Menger PM space $(X, F, t)$ satisfying the following properties.

1.f(X) $\subseteq \mathrm{T}(\mathrm{X})$ or $\mathrm{g}(\mathrm{X}) \subseteq \mathrm{S}(\mathrm{X})$

2. $F_{S a, T b}(x) \leq \varphi\left(F_{f a, g b}(x), F_{f a, S a}(x), F_{g b, T b}(x), F_{f a, T b}(x), F_{S a, g b}(x)\right)$

for every a,b $\in \mathrm{X}, \mathrm{x}>0$ and $\varphi \in F^{*}$.

If the pair (f, $S$ ) or $(g, T)$ is having the (E.A.) property then the pairs (f, S) and (g, T) both are having the common (E.A.) property.

Proof. Suppose that the pair (f, S) is having the property (E.A.), then there exists a sequence $\left\{x_{n}\right\}$ in $X$ such that

$$
\lim _{n \rightarrow \infty} f x_{n}=\lim _{n \rightarrow \infty} S x_{n}=t \text { for some } t \in X
$$

Since $f(X) \subset T(X)$, for each $\left\{x_{n}\right\}$ there exists $\left\{y_{n}\right\}$ in $X$ such that $f x_{n}=T y_{n}$

Therefore,

$$
\lim _{n \rightarrow \infty} f x_{n}=\lim _{n \rightarrow \infty} T y_{n}=t
$$

Now we claim that $\lim _{n \rightarrow \infty} g y_{n}=t$.

Let If possible $\lim _{n \rightarrow \infty} g y_{n} \neq t$, then

By (2) we have,

$F_{S x_{n}, T y_{n}}(x) \leq \varphi\left(F_{f x_{n}, g y_{n}}(x), F_{f x_{n}, S x_{n}}(x), F_{g y_{n}, T y_{n}}(x), F_{f x_{n}, T y_{n}}(x), F_{S x_{n}, g y_{n}}(x)\right)$

By taking limit as $n \rightarrow \infty$, we get

$$
\begin{aligned}
& F_{t, t}(x) \leq \varphi\left(F_{t, \lim _{n \rightarrow \infty} g y_{n}}(x), F_{t, t}(x), F_{\lim _{n \rightarrow \infty} g y_{n}, t}(x), F_{t, t}(x), F_{t,} \lim _{n \rightarrow \infty} g y_{n}(x)\right) \\
& 1 \leq \varphi\left(F_{t,} \lim _{n \rightarrow \infty} g y_{n}(x), 1, F_{\lim _{n \rightarrow \infty} g y_{n}, t}(x), 1, F_{t,} \lim _{n \rightarrow \infty} g y_{n}(x)\right)
\end{aligned}
$$

which is a contradiction to $\left(\mathbf{F}^{*} 1\right)$ and therefore $\lim _{n \rightarrow \infty} g y_{n}=t$.

Hence the pairs (f, S) and (g, T) are having the (E.A.) property.

Remark: The converse of Lemma 3.1 is not always true. 
Theorem 3.2 Let $f, g, S$ and $T$ be self-mappings on a Menger PM space $(X, F, t)$ such that the pair $(f, S)$ or $(g, T)$ is having the (E.A.) property. If

$$
\begin{aligned}
& \text { 1. } \mathrm{f}(\mathrm{X}) \subseteq \mathrm{T}(\mathrm{X}) \text { and } \mathrm{g}(\mathrm{X}) \subseteq \mathrm{S}(\mathrm{X}) \\
& \text { 2. } F_{S a, T b}(x) \leq \varphi\left(F_{f a, g b}(x), F_{f a, S a}(x), F_{g b, T b}(x), F_{f a, T b}(x), F_{S a, g b}(x)\right)
\end{aligned}
$$

for every a,b $\in \mathrm{X}, \mathrm{x}>0$ and $\varphi \in F^{*}$.

3. $\mathrm{S}(\mathrm{X})$ or $\mathrm{T}(\mathrm{X})$ is a closed subset of $\mathrm{X}$.

4. The pairs (f, S) and (g, T) are weakly compatible.

Then $\mathrm{f}, \mathrm{g}, \mathrm{S}$ and $\mathrm{T}$ have a unique common fixed point in $\mathrm{X}$.

Proof. If (f, S) or ( $g, T$ ) is having the (E.A.) property then it is clear form the lemma (3.1) that the pairs (f, S) and $(\mathrm{g}, \mathrm{T})$ are having the common (E.A.) property.

Thus there exist two sequences $\left\{x_{n}\right\}$ and $\left\{y_{n}\right\}$ in $X$ such that

$\lim _{n \rightarrow \infty} f x_{n}=\lim _{n \rightarrow \infty} S x_{n}=\lim _{n \rightarrow \infty} g y_{n}=\lim _{n \rightarrow \infty} T y_{n}=t$

for some $t \in X$

Now $\mathrm{S}(\mathrm{X})$ is a closed subset of $\mathrm{X}$, then there exists $u \in X$ such that $\mathrm{t}=\mathrm{Su}$.

If $t \neq f u$ then by (2), we have

$F_{S u, T y_{n}}(x) \leq \varphi\left(F_{f u, g y_{n}}(x), F_{f u, S u}(x), F_{g y_{n}, T y_{n}}(x), F_{f u, T y_{n}}(x), F_{S u, g y_{n}}(x)\right)$

By taking limit as $n \rightarrow \infty$, we get

$F_{t, t}(x) \leq \varphi\left(F_{f u, t}(x), F_{f u, t}(x), F_{t, t}(x), F_{f u, t}(x), F_{t, t}(x)\right)$

$1 \leq \varphi\left(F_{f u, t}(x), F_{f u, t}(x), 1, F_{f u, t}(x), 1\right)$

which is a contradiction to $\left(\mathbf{F}^{*} 2\right)$ and therefore $\mathrm{t}=\mathrm{fu}=\mathrm{Su}$.

Again since $\mathrm{f}(\mathrm{X}) \subseteq \mathrm{T}(\mathrm{X})$, there exists $v \in X$ such that $\mathrm{t}=\mathrm{Tv}$.

If $t \neq g v$ then by (2), we have

$F_{S u, T v}(x) \leq \varphi\left(F_{f u, g v}(x), F_{f u, S u}(x), F_{g v, T v}(x), F_{f u, T v}(x), F_{S u, g v}(x)\right)$

$F_{t, t}(x) \leq \varphi\left(F_{t, g v}(x), F_{t, t}(x), F_{g v, t}(x), F_{t, t}(x), F_{t, g v}(x)\right)$

$1 \leq \varphi\left(F_{t, g v}(x), 1, F_{g v, t}(x), 1, F_{t, g v}(x)\right)$

which is a contradiction to $\left(\mathbf{F}^{*} 1\right)$ and therefore $t=g v$.

Therefore $\mathrm{t}=\mathrm{fu}=\mathrm{Su}=\mathrm{Tv}=\mathrm{gv}$.

Since the pairs (f, S) and (g, T) are weakly compatible and fu

$=\mathrm{Su}, \mathrm{gv}=\mathrm{Tv}$,

Therefore $\mathrm{ft}=\mathrm{fSu}=\mathrm{Sfu}=\mathrm{St}, \quad \mathrm{gt}=\mathrm{gTv}=\mathrm{Tgv}=\mathrm{Tt}$.

If $t \neq f t$ then by (2), we have

$F_{S t, T v}(x) \leq \varphi\left(F_{f t, g v}(x), F_{f t, S t}(x), F_{g v, T v}(x), F_{f t, T v}(x), F_{S t, g v}(x)\right)$

$F_{t, t}(x) \leq \varphi\left(F_{f t, t}(x), F_{f t, t}(x), F_{t, t}(x), F_{f t, t}(x), F_{t, t}(x)\right)$

$1 \leq \varphi\left(F_{f t, t}(x), F_{f t, t}(x), 1, F_{f t, t}(x), 1\right)$

which is a contradiction to $\left(\mathbf{F}^{*} 2\right)$ and therefore $\mathrm{t}=\mathrm{ft}=\mathrm{St}$.
Finally if $t \neq g t$ then by (2), we have

$F_{S t, T t}(x) \leq \varphi\left(F_{f t, g t}(x), F_{f t, S t}(x), F_{g t, T t}(x), F_{f t, T t}(x), F_{S t, g t}(x)\right)$

$F_{t, t}(x) \leq \varphi\left(F_{t, g t}(x), F_{t, t}(x), F_{g t, t}(x), F_{t, t}(x), F_{t, g t}(x)\right)$

$1 \leq \varphi\left(F_{t, g t}(x), 1, F_{g t, t}(x), 1, F_{t, g t}(x)\right)$

which is a contradiction to $\left(\mathbf{F}^{*} 1\right)$ and therefore $\mathrm{t}=\mathrm{gt}=\mathrm{Tt}$.

Thus $\mathrm{t}=\mathrm{ft}=\mathrm{St}=\mathrm{gt}=\mathrm{Tt}$.

Hence $t$ is a common fixed point of $\mathrm{f}, \mathrm{g}, \mathrm{S}$ and $\mathrm{T}$.

For uniqueness let if possible $\mathrm{t}$ and $\mathrm{w}(\mathrm{t} \neq \mathrm{w})$ are two fixed point of $\mathrm{f}, \mathrm{g}, \mathrm{S}$ and $\mathrm{T}$.

then by (2), we have

$F_{S t, T w}(x) \leq \varphi\left(F_{f t, g w}(x), F_{f t, S t}(x), F_{g w, T w}(x), F_{f t, T w}(x), F_{S t, g w}(x)\right)$

$F_{t, w}(x) \leq \varphi\left(F_{t, w}(x), F_{t, t}(x), F_{w, w}(x), F_{t, w}(x), F_{t, w}(x)\right)$

$F_{t, w}(x) \leq \varphi\left(F_{t, w}(x), 1,1, F_{t, w}(x), F_{t, w}(x)\right)$

which is a contradiction to $\left(\mathbf{F}^{*} 3\right)$ and therefore $\mathrm{t}=\mathrm{w}$.

Thus $\mathrm{f}, \mathrm{g}, \mathrm{S}$ and $\mathrm{T}$ have a unique common fixed point in $\mathrm{X}$.

Hence the theorem.

Corollary 3.3 Let $\mathrm{f}$ and $\mathrm{S}$ be self-mappings on a Menger PM space $(X, F, t)$ such that the pair (f, S) is having the (E.A.) property. If

1. $F_{S a, S b}(x) \leq \varphi\left(F_{f a, f b}(x), F_{f a, S a}(x), F_{f b, S b}(x), F_{f a, S b}(x), F_{S a, f b}(x)\right)$

for every a,b $\in \mathrm{X}, \mathrm{x}>0$ and $\varphi \in F^{*}$.

2. $\mathrm{S}(\mathrm{X})$ is a closed subset of $\mathrm{X}$.

3. The pairs (f, $S$ ) is weakly compatible.

Then $\mathrm{f}$ and $\mathrm{S}$ have a unique common fixed point in $\mathrm{X}$.

Proof. By taking $\mathrm{f}=\mathrm{g}$ and $\mathrm{S}=\mathrm{T}$ in the theorem 3.2, we get the proof.

Corollary 3.4 Let f, g, S and T be self-mappings on a Menger PM space $(X, F, t)$ such that the pair $(f, S)$ and $(g, T)$ are having the (E.A.) property. If

1. $F_{S a, T b}(x) \leq \varphi\left(F_{f a, g b}(x), F_{f a, S a}(x), F_{g b, T b}(x), F_{f a, T b}(x), F_{S a, g b}(x)\right)$

for every a,b $\in \mathrm{X}, \mathrm{x}>0$ and $\varphi \in F^{*}$.

2. $\quad \mathrm{S}(\mathrm{X})$ and $\mathrm{T}(\mathrm{X})$ are closed subset of $\mathrm{X}$.

3. The pairs (f, $S)$ and $(g, T)$ are weakly compatible.

Then $\mathrm{f}, \mathrm{g}, \mathrm{S}$ and $\mathrm{T}$ have a unique common fixed point in $\mathrm{X}$.

Proof. It is clear form the lemma (3.1) that the pairs (f, S) and $(\mathrm{g}, \mathrm{T})$ are having the (E.A.) property.

Thus there exist two sequences $\left\{x_{n}\right\}$ and $\left\{y_{n}\right\}$ in $X$ such that

$\lim _{n \rightarrow \infty} f x_{n}=\lim _{n \rightarrow \infty} S x_{n}=\lim _{n \rightarrow \infty} g y_{n}=\lim _{n \rightarrow \infty} T y_{n}=t$

for some $t \in X$

Now $S(X)$ and $T(X)$ are closed subset of $X$, then there exists $u, v \in X$ such that $\mathrm{t}=\mathrm{Su}=\mathrm{Tv}$.

If $t \neq f u$ then by (2), we have

$F_{S u, T y_{n}}(x) \leq \varphi\left(F_{f u, g y_{n}}(x), F_{f u, S u}(x), F_{g y_{n}, T y_{n}}(x), F_{f u, T y_{n}}(x), F_{S u, g y_{n}}(x)\right)$

By taking limit as $n \rightarrow \infty$, we get 
$F_{t, t}(x) \leq \varphi\left(F_{f u, t}(x), F_{f u, t}(x), F_{t, t}(x), F_{f u, t}(x), F_{t, t}(x)\right)$

$1 \leq \varphi\left(F_{f u, t}(x), F_{f u, t}(x), 1, F_{f u, t}(x), 1\right)$

which is a contradiction to $\left(\mathbf{F}^{*} 2\right)$ and therefore $\mathrm{t}=\mathrm{fu}=\mathrm{Tv}=\mathrm{Su}$. The remaining proof is similar to that of theorem 3.2.

Corollary 3.5 Let f, g, S and T be self-mappings on a Menger PM space $(X, F, t)$ such that the pair $(f, S)$ and $(g, T)$ are having the (E.A.) property. If

1. $F_{S a, T b}(x) \leq \varphi\left(F_{f a, g b}(x), F_{f a, S a}(x), F_{g b, T b}(x), F_{f a, T b}(x), F_{S a, g b}(x)\right)$

for every a,b $\in \mathrm{X}, \mathrm{x}>0$ and $\varphi \in F^{*}$.

2. $\overline{S(X)} \subset X$ and $\overline{T(X)} \subset X$.

3. The pairs (f, $S)$ and $(g, T)$ are weakly compatible. Then $\mathrm{f}, \mathrm{g}, \mathrm{S}$ and $\mathrm{T}$ have a unique common fixed point in $\mathrm{X}$.

Proof. Proof is similar to that of corollary 3.5.

\section{ACKNOWLEDGMENTS}

We are thankful to Prof. L. N. Joshi and Prof. J. N. Chauhan for their cooperation in the preparation of this paper. We are also thankful to the numerous referees for their helpful and valuable comments.

\section{REFERENCES}

[1] K. Menger, Statistical metrics, Proc. Nat. Acad. Sci. U.S.A. 28 (1942), 535-537.

[2] V.M. Sehgal, Some fixed point theorems in function analysis and probability, Ph.D dissertation, Wayne State Univ. Michigan (1966).

[3] V.M. Sehgal and A.T. Bharucha-Reid, Fixed points of contraction mappings on probabilistic metric spaces, Math. Systems Theory 6 (1972), 97-102.

[4] H. Sherwood, Complete probabilistic metric spaces, Z. wahrscheinlichkeits theorie and verw. Grebiete 20 (1971), 117-128.

[5] V.I. Istratescu and I. Sacuiu, Fixed point theorem for contraction mappings on probabilistic metric spaces, Rev. Roumaine Math. Pures. Appl. 18 (1973), 1375-1380.

[6] I. Altun and D. Turkoglu, Some fixed point theorems on fuzzy metric spaces with implicit relations, Commun. Korean Math. Soc., 23(1)(2008), 111-124.

[7] G. Jungck, "Compatible mappings and common fixed points," International Journal of Mathematics and Mathematical Sciences, vol. 9, no. 4, pp. 771-779, 1986.

[8] R. P. Pant, "Common fixed points of non commuting mappings," Journal of Mathematical Analysis and Applications, vol. 188, no. 2, pp. 436-440, 1994.

[9] M. Aamri and D. El Moutawakil, "Some new common fixed point theorems under strict contractive conditions," Journal of Mathematical Analysis and Applications, vol. 270, no. 1, pp. 181-188, 2002.

[10] Y. Liu, J.Wu, and Z. Li, "Common fixed points of singlevalued and multi valued maps," International Journal of Mathematics and Mathematical Sciences, vol. 2005, no. 19, pp. 3045-3055, 2005.

[11] M. Imdad, J. Ali, and L. Khan, "Coincidence and fixed points in symmetric spaces under strict contractions," Journal of Mathematical Analysis and Applications, vol. 320, no. 1, pp. 352-360, 2006.

[12] I. Kubiaczyk and S. Sharma, "Some common fixed point theorems in Menger space under strict contractive conditions," Southeast Asian Bulletin of Mathematics, vol. 32, no. 1, pp. 117-124, 2008.

[13] A. Branciari, "A fixed point theorem for mappings satisfying a general contractive condition of integral type," International Journal of Mathematics and Mathematical Sciences, vol. 29, no. 9, pp. 531-536, 2002.

[14] A. Aliouche, "A common fixed point theorem for weakly compatible mappings in symmetric spaces satisfying a contractive condition of integral type," Journal of Mathematical Analysis and Applications, vol. 322, no. 2, pp. 796-802, 2006.

[15] A. Djoudi and A. Aliouche, "Common fixed point theorems of Gregus type for weakly compatible mappings satisfying contractive conditions of integral type," Journal of Mathematical Analysis and Applications, vol. 329, no. 1, pp. 31-45, 2007.

[16] B. E. Rhoades, "Two fixed-point theorems for mappings satisfying a general contractive condition of integral type," International Journal of Mathematics and Mathematical Sciences, no. 63, pp. 4007-4013, 2003.

[17] D. Turkoglu and I. Altun, "A common fixed point theorem for weakly compatible mappings in symmetric spaces satisfying an implicit relation," Boletin de la Sociedad Matematica Mexicana. Tercera Serie, vol. 13, no. 1, pp. 195205, 2007.

[18] P. Vijayaraju, B. E. Rhoades, and R. Mohanraj, "A fixed point theorem for a pair of maps satisfying a general contractive condition of integral type," International Journal of Mathematics and Mathematical Sciences, no. 15, pp. 2359-2364, 2005.

[19] T. Suzuki, "Meir-Keeler contractions of integral type are still Meir-Keeler contractions," International Journal of Mathematics and Mathematical Sciences, vol. 2007, Article ID 39281, 6 pages, 2007.

[20] J. Ali and M. Imdad, "An implicit function implies several contraction conditions," Sarajevo Journal of Mathematics, vol. 4(17), no. 2, pp. 269-285, 2008. 